\title{
Recensión de Libros
}

\section{Neurotrauma y neurointensivismo. Andrés Rubiano y Rafael Pérez. Distribuna Editorial Médica. Bogotá. 2007.}

Es un libro extenso, cercano a las 800 páginas, que trata de forma detallada diversos temas en torno a los traumatismos, tanto cráneo-encefálicos con medulares. La tercera parte está dedicada a los cuidados intensivos del paciente neurológico.

Después de unos capítulos dedicados a nociones bioestadísticas y de la valoración o peso de los estudios clínicos, entra de lleno en la cuestión clínica. En la primera parte, que se refiere al traumatismo craneoencefálico, se incluye la fisiopatología del traumatismo grave, (con la PIC y edema cerebral), y el tratamiento de la víctima en todas sus fases, prehospitalaria, Urgencias y en la Unidad de Cuidados Intensivos. Dentro de su detallada exposición, incluyen aspectos sobre controversias actuales, por ejemplo el uso de infusión de coloides o cristaloides o bien del tratamiento de los hematomas subdurales crónicos o de las craniectomías descompresivas.

Hay un detallado capítulo sobre monitorización neurológica, con asesoramiento español (Dra. M.A. Poca) y otros que comprenden los estudios con TAC y RM, Doppler, soporte nutricional, pronóstico, rehabilitación y alteraciones psiquiátricas o deterioro grave y persistente de conciencia. Hay dos capítulos sobre la neurotraumatología infantil y otro sobre heridas por armas de fuego, este último con todos los detalles sobre armas de corto o largo alcance y calibre de los proyectiles, algo que no es fácil encontrar en nuestros medios.

En la sección segunda o de traumatismos raquimedulares se sigue el mismo camino, en lo que se refiere a la fisiopatología, conducta prehospitalaria, diagnóstico por imagen, fijación quirúrgica, tratamiento médico y ensayos clínicos recientes, soporte nutricional, rehabilitación y tratamiento psiquiátrico. Hay unos capítulos especiales dedicados a la terapia con células madre y a la investigación clínica de estas lesiones medulares, con consejos sobre metodología para aumentar la fiabilidad de los estudios, efectividad de los tratamientos médicos actuales y con exposición de las líneas de investigación abiertas en torno al uso de factores neurotróficos o prevención de la apoptosis.
La última parte del libro se centra en los cuidados intensivos, de manera expresa. Comienza con un recuerdo anatómico del sistema nervioso y con las bases de fisiología cerebral, transmisión sináptica, flujo cerebral, barrera hematoencefálica, localización de funciones y redes neuronales. Insiste en el edema cerebral y en las acuaporinas, en la monitorización, uso del Doppler, iconografía y con las bases de neuroanestesia en estos pacientes. Dentro de esta sección, no se limita a los traumatismos sino que incluye otras patologías del sistema nervioso, tales como las hemorragias, (subaracnoidea y parenquimatosa), ictus oclusivos, hidrocefalia o estados epilépticos. Presta atención a la profilaxis de la trombosis venosa y del embolismo pulmonar, al soporte ventilatorio, a la neumonía nosocomial, a las alteraciones metabólicas, infecciones, úlceras por decúbito y la fisioterapia del paciente ingresado en la UCI.

También deben constar algunos reparos en la recensión. Uno de ellos es la repetición de cuestiones en diversos capítulos. Por ejemplo, la Escala de Coma de Glasgow con la que el lector se encuentra varias veces, el estudio con Doppler, etc. También hay que hacer algunas objeciones en relación con el uso de anglicismos. Es continuo el uso de "severo" en los traumatismos, cuando la Academia recomienda que se traduzca por "grave" o bien por "intenso o fuerte", si se trata de dolor. Tampoco debe usarse el término "injuria" -que es apropiado cuando se trata de un daño o agravio verbal- y que, en su lugar, debe traducirse por "lesión". Otro consejo para futuras ediciones sería que hubiera una nota aclaratorio de los acrónimos o abreviaturas utilizadas al final de cada capítulo o una página general con todos ellos.

Sin embargo, hechas estas salvedades, creo que el libro tiene mucho valor, porque aporta una información amplia sobre temas que interesan a neurocirujanos, neurólogos, anestesistas e intensivistas, con análisis de cuestiones discutibles, que tienen en cuenta la metodología de los trabajos y con una rica y reciente aportación bibliográfica.

M. Poza 